\title{
Quantification of pumping rate of Chironomus plumosus larvae in natural burrows
}

\author{
M. R. Morad • A. Khalili • A. Roskosch • \\ J. Lewandowski
}

Received: 1 October 2008/ Accepted: 15 June 2009/Published online: 30 June 2009

(C) The Author(s) 2009. This article is published with open access at Springerlink.com

\begin{abstract}
This paper investigates and compares experimentally determined water velocity field above natural macrozoobenthos burrows generated by Chironomus Plumosus larva during their bio-irrigation activity. All experiments were carried out using particle image velocimetry and performed in mesocosms filled with sediment burrowed by larvae, and the water velocity fields near the inlets and outlets of the U-shaped burrows were measured. From water velocity data the average volumetric flow rates between 54.6 and $61.1 \mathrm{~mm}^{3} / \mathrm{s}$ were calculated. Assuming an average burrow diameter of $2.25 \mathrm{~mm}$, the volumetric flow rates suggest the average flow velocities through burrows during the pumping period between 13.7 and $15.4 \mathrm{~mm} / \mathrm{s}$. Two additional interesting phenomena could also be shown by analyzing the flow field generated by the larva. The analysis of the amount of tracers used for visualiza-
\end{abstract}

M. R. Morad · A. Khalili ( $₫)$

Max Planck Institute for Marine Microbiology, Celsiusstr. 1, 28359 Bremen, Germany

e-mail: akhalili@mpi-bremen.de

A. Khalili

Jacobs University, Bremen Campus Ring 1, 28759

Bremen, Germany

A. Roskosch · J. Lewandowski

Leibniz-Institute of Freshwater Ecology and Inland

Fisheries, Müggelseedamm 310, 12587 Berlin, Germany tions revealed that some of the tracer particles added to the water must have been consumed along their path from the inlet toward the outlet, hinting clearly to the so-called filter-feeding action of $C$. plumosus. The second phenomenon is due to the form of motion C. plumosus generates. By careful flow visualizations it was found that unlike other organisms such as Urechis caupo that use peristaltic body contractions, C. plumosus worms its body sinusoidally catapulting the fluid far into the overlying water body. This action is of ecological advantage for it avoids generating short oxygen circuits for their respiration and filter feeding.

Keywords Bio-irrigation - Macrozoobenthos · Tube dwelling $\cdot$ C. Plumosus $\cdot$ Particle image velocimetry

\section{Introduction}

Bio-irrigation caused in sediment-water boundary layers by tube-dwelling macrozoobenthos species is an important process for the exchange of dissolved substances between pore water and the overlying water body. Large numbers of macroinvertebrates inhabiting limnic and marine sediment-water boundary layers have a major influence on biogeochemistry, microbial community structure and early diagenetic processes. Some macrozoobenthos species burrow 
tubes into the sediment, and only some burrowing species pump water through their burrows. This pumping activity is called bio-irrigation (Anderson and Meadows 1978) and might cause, in addition to the flow of water through the burrow, an advective and diffusive transport into the surrounding sediment as reported by Meysman et al. (2006) for J-shaped burrows of Arenicola marina in sandy sediments. Thus, $\mathrm{O}_{2}$ oxidizes the anaerobic sediments, and often electron acceptors and nutrients are introduced into the sediment. Furthermore, dissolved nutrients such as phosphate, ammonium and other metabolites are transported from the pore water into the overlying waterbody by bio-irrigation. Microbial consequences and biogeochemical impacts of bio-irrigation in benthic sediments have been long recognized and described in studies such as those of Andersson et al. (1988), Johnson et al. (1989), Aller (1994), Stief and de Beer (2002), and Lewandowski and Hupfer (2005). Some of such studies are devoted to mathematical modeling of hydraulics and hydrodynamics of bioirrigation caused by tube-dwelling species, e.g., Boudreau et al. (2001), Furukawa et al. (2001), Koretsky et al. (2002), Timmermann et al. (2002) and Meile et al. (2003). However, there is still a lack of experimental investigations of hydraulic and hydrodynamic processes and of quantification of flux rates pumped into or out of the burrows by tubedwelling macrozoobenthos species.

Bio-irrigation-induced water fluxes depend on burrow shape, sediment conditions and ventilation activities of the macrozoobenthos species. Many different types of burrows constructed by a variety of tube-dwelling species can be found in marine and limnic sediments. Examples of bio-irrigators are the acorn worm Schizocardium sp. from Mississippi Bay that construct U- or V-shaped burrows penetrating the sediment to up to $9 \mathrm{~cm}$ (Furukawa et al. 2001) or the lugworm A. marina one of the most conspicuous marine macrozoobenthos species irrigating 20-30 cm deep J- or U-shaped burrows in the North Frisian Wadden Sea (Meysman et al. 2006; Timmermann et al. 2006; Volkenborn et al. 2007). The emphasis of this paper, however, lies on the larva of the midge Chironomus plumosus, which occurs in oxygendeficient lake sediments in high densities $(\leq 4,000$ ind. $\mathrm{m}^{-2}$; Andersen and Jensen 1991). This larva constructs periodically ventilated U-shaped burrows down to $15 \mathrm{~cm}$ depth with an inlet and an outlet at the sediment surface normally. In literature (e.g., Graneli 1979; Polerecky et al. 2006; Lewandowski et al. 2007), C. plumosus is an often-mentioned and well-described example for bio-irrigation activity. However, despite their high abundances and their significant ecological role for processes both within and above the sediment, measurements of pumping rates of $C$. plumosus are rare in published literature (Leuchs 1986; Kißner et al. 2003).

There is still a lack of knowledge on the hydraulics and hydrodynamics of bio-irrigation activities due to difficulties associated with the visualization and quantification of flow in small burrows. A prerequisite for the quantification of the hydrodynamic fluxes caused by bio-irrigation is the measurement of the flow velocities inside the macrozoobenthos burrows or at their inlets and outlets. Recently, Riisgård and Larsen (2005) have reviewed measuring of water pumping and the analysis of flow generated by burrowing deposit- and filter-feeding zoobenthos. They report the use of a variety of invasive and non-invasive methods to measure flow rate, pumping pressure and pumping power of the burrowing zoobenthos. For example, the feasibility of visualizing the flow generated by the tube-dwelling shrimp Callianassa has been shown using particle image velocimetry (PIV) by Stamhuis and Videler (1998) in an artificial transparent tube, in which a unidirectional laminar and steady flow in the upstream with a parabolic cross-section was generated. Up to now, PIV was only applied to determine flow velocities in such artificial burrows. However, to determine the flow in natural burrows, PIV must be applied above the burrow inlets and burrow outlets.

The quantification of the pumping activity is the first step for both understanding the role of larvae's activity in the ecosystem as well as developing better models to mimic their biogeochemical impacts. Therefore, the aim of the present study is to quantify the advective transport generated by the larvae's body motions using non-invasive experimental PIV. To do this, the flow rate of water pumped into or out of the burrows has been calculated from the velocity profiles above burrow inlets and outlets. By comparing measurements in natural versus controlled burrows and introducing the stream tube concept, the volumetric flow rate was derived as a representative quantity for the advective transport triggered by larvae's motion. 


\section{Materials and methods}

Sediment and water

The experiments were performed with sediments from Lake Müggelsee in Berlin, Germany. Lake Müggelsee is a shallow eutrophic lake with an area of $7.3 \mathrm{~km}^{2}$ and a mean depth of $4.9 \mathrm{~m}$ (Driescher et al. 1993). The Müggelsee is a polymictic lake; thus, its water is mixed most times in the year (Nixdorf 1994; Eckert and Walz 1999; Kozerski and Kleeberg 1998). The lake water temperature in summer is often $\geq 20^{\circ} \mathrm{C}$. According to the measurements at the sampling day (June, 25th 2007) the temperature was $21.5^{\circ} \mathrm{C}$ from 0 to $7.5 \mathrm{~m}$, maximum water depth of the lake. Average temperature based on weekly measurements from June to September 2007 was $19^{\circ} \mathrm{C}$. As the temperature of Lake Müggelsee has been showing a long-term increase due to climate change (Wilhelm et al. 2006), the experiments were performed at room temperature of $22^{\circ} \mathrm{C}$.

Sediments were collected with a sediment grab from about $5 \mathrm{~m}$ depth a few days before the experiments were started. To remove macrozoobenthos and big particles, the sediment was sieved using $\leq 2 \mathrm{~mm}$ mesh size and stored in closed opaque containers at $10^{\circ} \mathrm{C}$ until needed. The water used in the experiments was bank filtrate taken from the same lake.

\section{Macrozoobenthos}

Chironomus plumosus larvae (4th instar, length ca. $2 \mathrm{~cm}$ ) were obtained by sieving the sediment of Lake Müggelsee. They were identified based on adult males using the key of Langton and Pinder (2007), for it is not possible to identify females. Additionally, some larvae were identified following the key of Epler (2001). To slow down the larval development between the time of sample collection and the start of experiments, they were kept 4 days at $10^{\circ} \mathrm{C}$ in aerated mesocosms filled with sediment and water from the lake. Twenty-four hours before the start of experiment, larvae were kept at $22^{\circ} \mathrm{C}$ so the larvae could adapt to their ambient temperatures. After placing them in the mesocosms at $22^{\circ} \mathrm{C}$, the larvae were allowed for few days to build their burrows as well as adapt to the experimental conditions such that the larvae could construct burrows. In all cases, clear burrow inlets and outlets were visible after about
3 days from the time they were placed in the mesocosm. The larvae are known to build single U-tubes in muddy sediments, the burrow lengths varying between 10 and $30 \mathrm{~cm}$. Burrows are stabilized with a secretion. Most of the time, C. plumosus stays in the lower part of the burrow pumping water periodically. It performs undulating movements to provide oxygen for respiration and phytoplankton for food from the overlying water body. For the latter purpose the larva spins a conical net in its burrow. During non-pumping periods C. plumosus is either resting or moving inside the burrow, grazing microorganisms from burrow walls or feeding on the conical net with entrapped phytoplankton (Pinder 1986; Leuchs and Neumann 1990).

\section{Experimental setup}

The experimental setup consists of a rectangular open mesocosm of size $25 \times 30 \times 5 \mathrm{~cm}^{3}$ with the side walls made of transparent Duran glass. The mesocosm was filled by sediment up to $15 \mathrm{~cm}$ (Fig. 1). After sediment deposition, water was slowly added to the mesocosm to a height of ca. $25 \mathrm{~cm}$ avoiding stirring and resuspension of the sediment. The heights of the sediment and the overlying water were kept constant for all experiments.

The experiments were conducted for three different setups shown in Table 1. In the setup I the larvae were placed inside a mesocosm containing only sediment where the larvae could freely build their burrows. To ensure having at least one burrow with a proper inlet and an outlet, a few larvae were initially placed into the mesocosm. The burrow functionality was checked using dye injection tests. PIV measurements were made only after ensuring the existence of burrows with a proper inlet and an outlet. In setup II, wire gauze U-tubes (with a diameter of $1 \mathrm{~cm}$ and a length of $25 \mathrm{~cm}$ ) were filled with sediment, and a larva was located at each tube entrance to construct its burrow inside the tube. Setup III, finally, consisted of transparent Tygon plastic U-tubes with a solid wall (and a length of $25 \mathrm{~cm}$ ), filled only with water (no sediment). The diameter of the Tygon plastic tubes was $3.2 \mathrm{~mm}$, because larvae could not survive in smaller tubes with inflexible walls. Compared with setups I and II, setup III provides a more controlled environment, as the larva must reside in a tube of a predefined shape containing water, only. In setup I 
Fig. 1 Left image experimental setup showing a CCD camera, a diode laser, and the sediment tank filled partially with sediment and overlying water. The larva is indicated in the burrow. The chimney-like elevation near the burrow inlet is constructed by the burrowing larva and is captured by the CCD camera (right image)

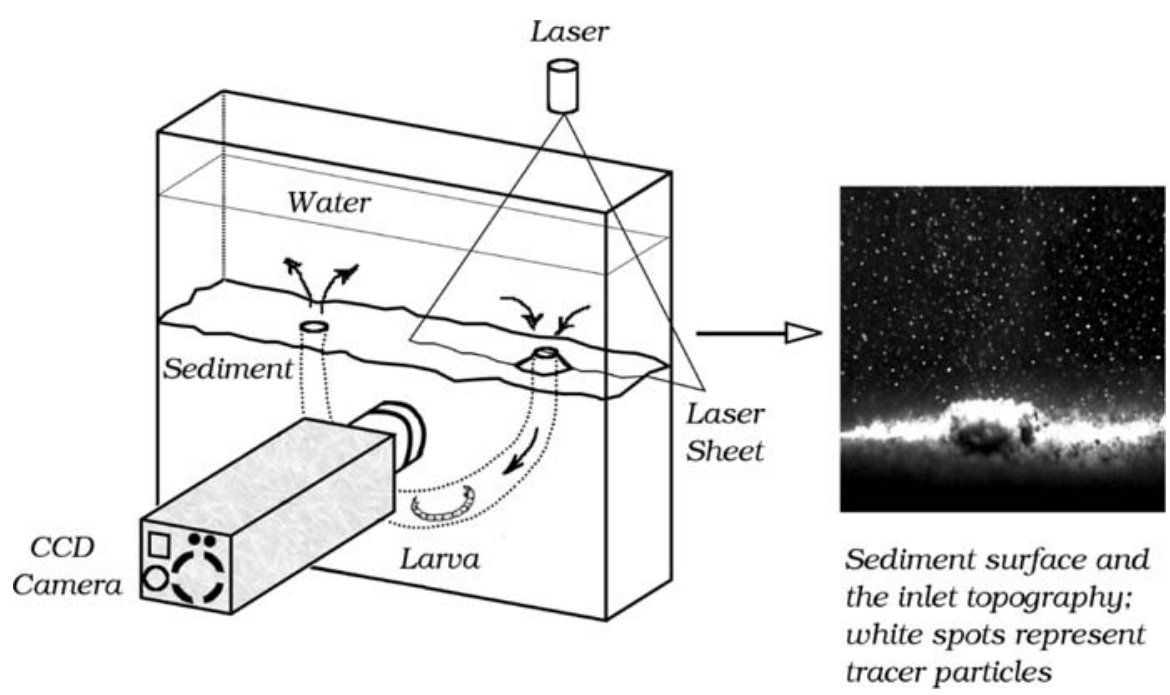

Table 1 Three different experimental setups used for the flow visualizations

\begin{tabular}{lll}
\hline Setup & Additional device & Filled with \\
\hline Setup I & None (sediment only) & - \\
Setup II & Wire gauze U-tube & Sediment \\
Setup III & Tygon plastic U-tube with solid wall & Water only \\
\hline
\end{tabular}

(natural burrow), six larvae were placed in 2 mesocosms (each three in one mesocosm). Setup II (quasinatural burrow) contained one mesocosm with six tubes, each filled with natural sediment and one larva. However, in setup III (artificial burrow) a single mesocosm contained three tubes, each filled with one larva. Hence, in total 15 larvae were used.

For the visualization of the flow generated by the pumping activity of larva, PIV was used. PIV is a nonintrusive visualization and measurement method, for which following optical configurations are required: a laser light source, optical devices for conversion construction of a light sheet from the light source, tracer particles that are added to the ambient fluid and finally a digital camera that records the location of the tracer particles at two different time steps separated by a very small time delay. These two successive PIV images are then used to obtain the velocity of the tracer particles. Because the tracers have the same density as that of the ambient fluid, the tracer velocities are considered as the velocity of the fluid particles, hence capturing the entire illuminated 2-D field. The image analysis is performed by a mathematical tool. The results of the velocity measurements can be post-processed to derive additional parameters describing the flow.

Since the measurements were performed in the water layer near the entrance or exit of the burrow, there was no difficulty in optical access to the region of interest. As the sediment was dark due to its nature, no reflections were generated when being imposed to laser light, providing an optimal condition for PIV measurements. To illuminate region of interest, a $40 \mathrm{~mW}, 658 \mathrm{~nm} \mathrm{CW}$ diode laser was mounted above the mesocosm and operated in pulse mode. A SensiCam PCO camera $(1,024 \times 1,280$ pixel resolution) was installed perpendicular to the plane of the laser sheet to record the particle motion in the field of view, as illustrated in Fig. 1. Full-frame images were acquired and transferred to a computer via a frame grabber. Polyamide particles with a diameter of $20 \mu \mathrm{m}$ were added to the water as seeding tracers. To observe the flow near the burrow inlet or outlet, a lens with a focal length of $f=5 \mathrm{~cm}$ was employed and connected to an extension tube between the CCD camera and the lens. To obtain high quality images for the velocity measurements, an optimized exposure laser pulse time $\left(t_{\mathrm{e}}\right)$ as well as the corresponding pulse separation time step $\left(t_{\mathrm{s}}\right)$ are needed. The time $t_{\mathrm{e}}$ is the width of each exposed laser pulse during the light emission while the time $t_{\mathrm{s}}$ is the time difference between two successive pulses. Because the fluid velocity into (or out of) the burrow is drastically changed by the status of the larva's pumping activity, optimal $t_{\mathrm{e}}$ and $t_{\mathrm{s}}$ had to be found in experiments. For the same reason, a set of 
different tests was conducted resulting in $t_{\mathrm{e}}=5 \mathrm{~ms}$ and $t_{\mathrm{s}}=10 \mathrm{~ms}$. For each experiment, a total number of 260 image pairs (the maximum number of images that PC RAM could handle) were taken resulting in a total observation time of $40 \mathrm{~s}$. To avoid temperature effects on the pumping activity of the larva, all experiments were performed at a constant room temperature $\left(23 \pm 1^{\circ} \mathrm{C}\right)$. Furthermore, the mesocosms were aerated with membrane pumps in the time between two subsequent PIV measurements but not during the measuring time itself. This is needed to avoid turbulence that could seriously disturb the measurements. The spatial resolution used for PIV images was $66-95$ pixels $/ \mathrm{mm}$. Also an additional subpixel interpolation was implemented. Hence, the uncertainty of the present PIV measurement was estimated to be $<4 \%$.

\section{Results}

Visualization of the velocity field

A typical flow visualization of the velocity pattern above the burrow inlet of the setup I (only sediment without artificial U-tube), as demonstrated in Fig. 2, shows the velocity vectors within a pumping period. High velocities generated near the entrance region are shown as large arrows. The maximum intensity in the color map denotes a typical converging nozzle flow. In the converging area, fluid is sucked from the ambient water and directed into the burrow. As shown in the color map, the maximum local velocity obtained during pumping activity is $27.5 \mathrm{~mm} \mathrm{~s}^{-1}$. However, it should be mentioned that the maximum velocity was changing as a function of time of the experiment. The figure also shows that the far field flow is not affected by the pumping activity.

With a fixed length, shape and location of inlet and outlet, the second setup (wire gauze U-tube filled with sediment) provided a controlled system for PIV measurements at inlet and outlet of the same burrow. There exists a diverging flow pattern near the outlet (Fig. 3b), which has the typical, well-known pattern referred to as 'jet' or 'plume' structure. The jet flow is characterized by a dominant axial flow overlapped with a lateral shear zone. This structure is clearly visible by the propagating and diverging velocity field shown in the figure. The opposite process namely a convergent flow pattern near the inlet is the direct consequences (Fig. 3a). The maximum inlet velocity in setup II was $26.5 \mathrm{~mm} \mathrm{~s}^{-1}$, whereas the

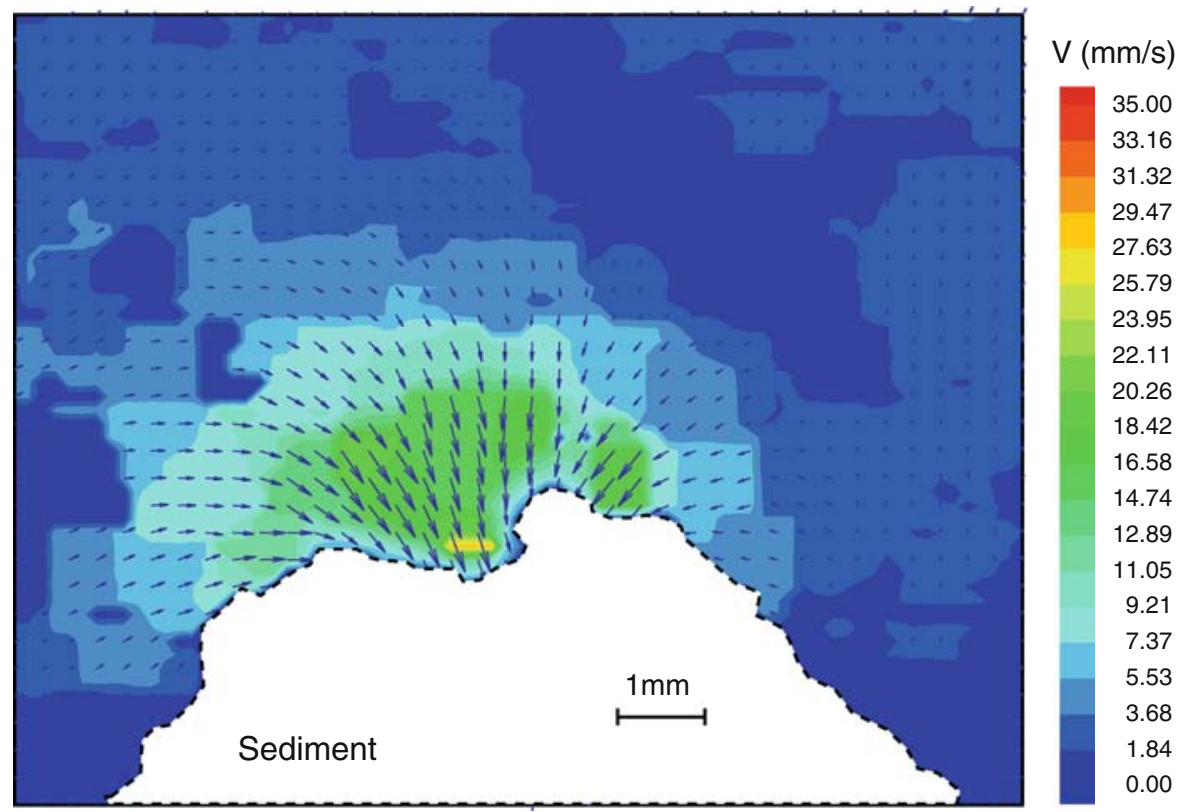

Fig. 2 Velocity vector field (arrows) and the color map of flow magnitudes (red stands for maximum, whereas dark blue represents the minimum) above a burrow inlet of setup I 
Fig. 3 The contours of the velocity (color maps) and the velocity vector plots (arrows) at a the inlet and at b the corresponding outlet of setup II (wire gauze U-tube filled with sediment) (a)

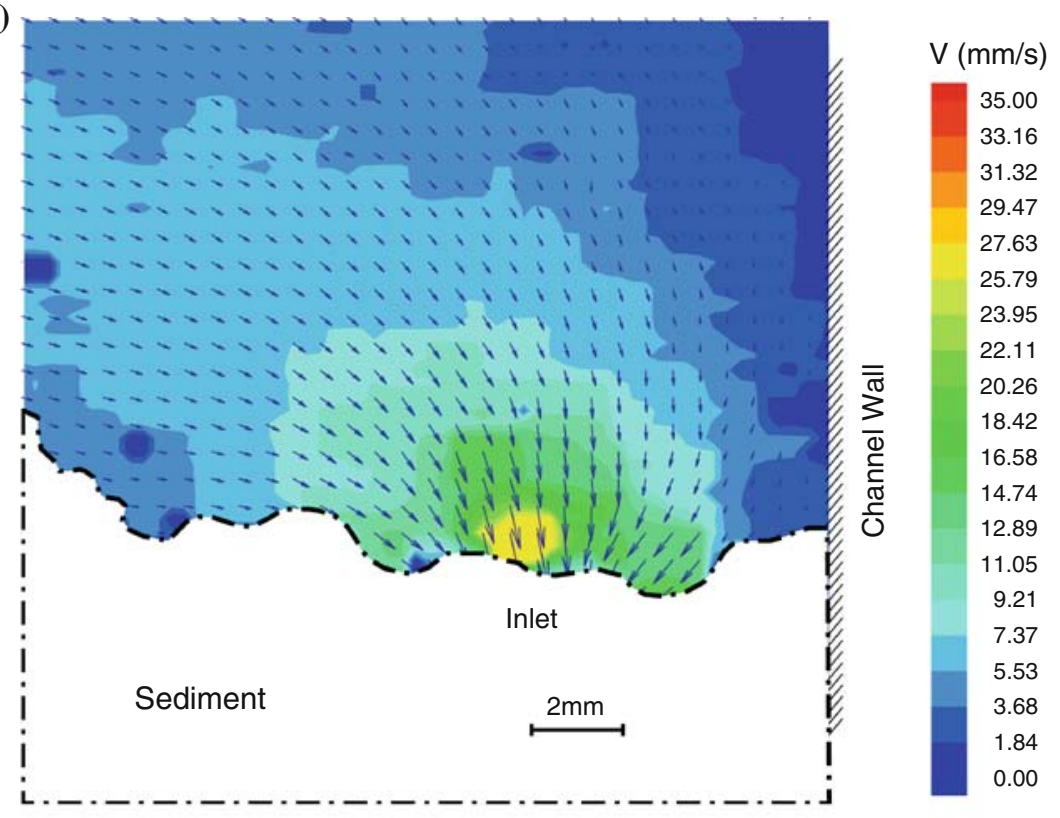

(b)

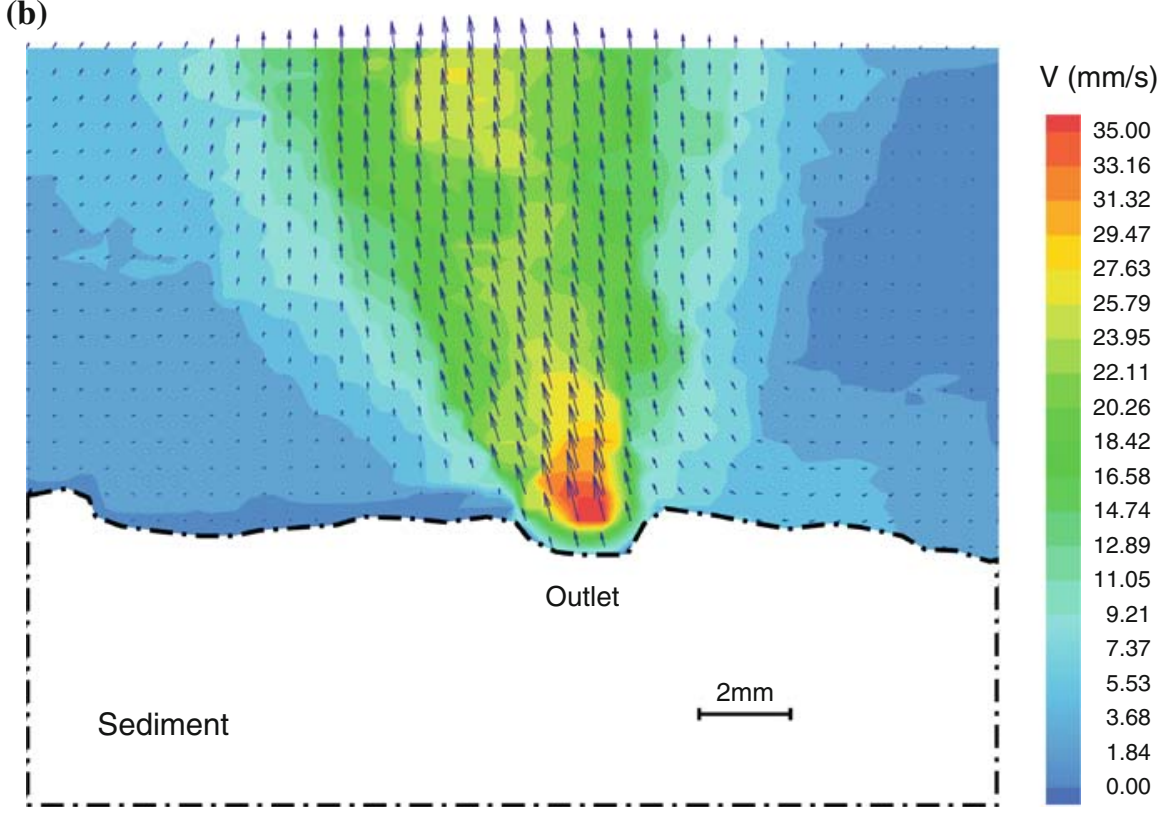

maximum outlet velocity was $34.1 \mathrm{~mm} \mathrm{~s}^{-1}$. Note that the images are taken at different times.

Besides, we observed an interesting feature of a pulsating flow generated by the $C$. plumosus via analyzing the outlet flow of the setup II (Fig. 3), found in setups I and III, too. By extracting only the higher velocity contours, two higher velocity regions with local extremes become visible (see the two regions framed by dashed lines in Fig. 4). As shown, the velocity had a local maximum near the outlet. The flow velocity decreased to a minimum but increased again further away in the flow direction. This effect was noticed also when the pumping activity of the larva was tested with color tracers. After tracer was 
Fig. 4 The pulsing pattern in the velocity contours near the outlet caused by the pumping mechanism of C. plumosus larva

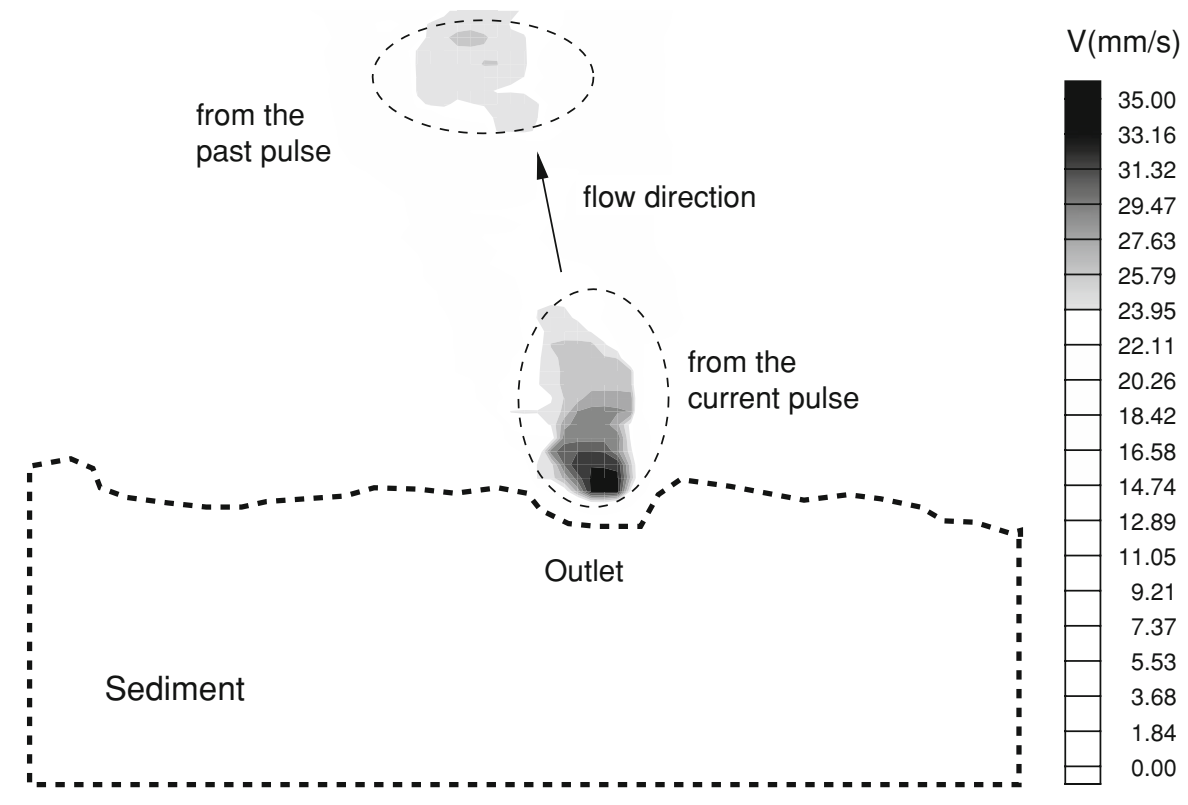

Fig. 5 The contours and vectors of the velocity at an inlet of setup III (Tygon U-tube without sediment)

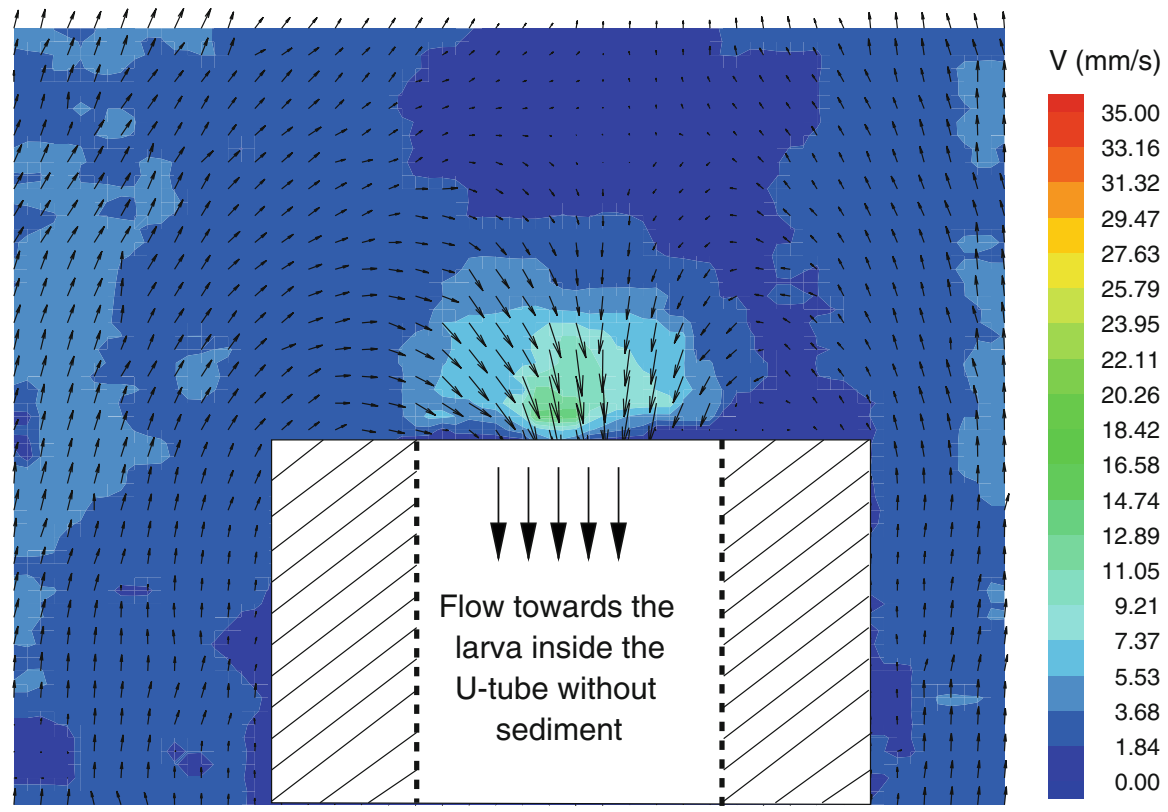

added above the inlet and pumped through the burrow, the color left the burrow outlet as an undulating plume. The existence of two large velocities inside both framed regions is a clear hint of pulsation.

The velocity field at the inlet of setup III (Tygon U-tube with solid wall filled with water only) was also measured. Typical results obtained at the inlet can be seen in Fig. 5. The spatial velocity gradients are not as intense as those in other two setups. The maximum velocity at the inlet reached $13.5 \mathrm{~mm} \mathrm{~s}^{-1}$.

Note that all velocities reported so far were instantaneous velocities, and that for the quantification of the volumetric flow rate, time-averaged velocities are required. Hence, for the calculation of the time-averaged maximum velocity near the inlets (Table 2), velocity data of all PIV-image pairs during 
Table 2 Time-averaged maximum velocity measurements $\left(\bar{v}_{\max }\right)$ by PIV in all setups with the corresponding standard deviations at burrow inlets during pumping periods

\begin{tabular}{llll}
\hline Setup & $\bar{v}_{\max }(\mathrm{mm} / \mathrm{s})$ & $\sigma_{v_{\max }}$ & $n_{\mathrm{i}}$ \\
\hline Setup I & 22.3 & 7.4 & 216 \\
Setup II & 30.5 & 7.3 & 200 \\
Setup III & 17.9 & 5.4 & 206 \\
\hline
\end{tabular}

$\sigma_{v_{\max }}$, standard deviation in the maximum velocity; $n_{\mathrm{i}}$, number of PIV-image pairs

the entire pumping periods by the larvae have been considered.

\section{Volumetric flow rate}

In order to calculate the total volumetric flow rate displaced by the larva, the concept of a stream tube above the burrow inlet was introduced. The stream tube contained all streamlines entering the burrow (see Fig. 6). As indicated in the figure, a circular cross-section has been assumed. The perimeter of the cross-section is tangential to the outermost streamlines. The volumetric flow rate within any crosssection of such a stream tube is constant. The volumetric flow rate $(Q)$ over the cross-section can be calculated by integration of the velocity over the cross-section of the stream tube using

$Q=2 \pi \int_{0}^{r_{\mathrm{c}}} v_{n} r \mathrm{~d} r$

with $v_{n}, r$ and $r_{\mathrm{c}}$ denoting the velocity component normal to the cross-section determined for the plane

Far-field fluid layer

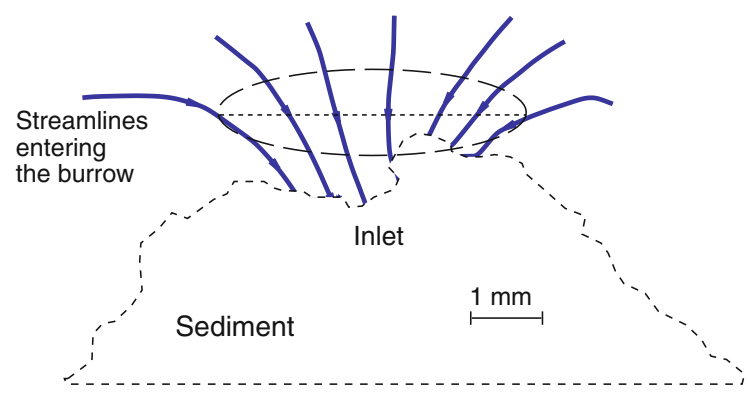

Fig. 6 Streamlines obtained from the measurement plane. The circle denotes the cross-section of the streamlines entering the burrow with its diameter shown as dashed line of the laser sheet, the radial coordinate from the center of the circular cross-section and the radius of the stream tube, respectively. Because the volumetric flow rate is constant, by knowing the flow rate and the diameter of the burrow, an average velocity, $v_{\mathrm{av}}$, can be defined. If the diameter of the burrow is denoted by $d_{\mathrm{b}}$, the average velocity can be given as

$v_{\mathrm{av}}=\frac{8}{d_{\mathrm{b}}^{2}} \int_{0}^{r_{\mathrm{c}}} v_{n} r \mathrm{~d} r$.

From the velocity field of each pair of images, a volumetric flow rate was calculated by Eq. (1) corresponding to one instance of time. Hence, a time-averaged volumetric flow rate $\bar{Q}$ could be also obtained from averaging the varying flow rates with time (Table 3).

We would like to emphasize that the standard deviations in both time-averaged maximum velocity $\left(\sigma_{v_{\max }}\right)$ outside the inlet (Table 2) and time-averaged volumetric flow rate $\left(\sigma_{Q}\right)$ through the burrows (Table 3) from one side and the measurement uncertainties (mentioned in "Experimental Setup") from the other side are not the same. While the former is the deviation of the time-oscillating velocity data from its mean value, the latter is due to measurement uncertainties of the present PIV.

\section{Discussion}

As mentioned, the quantification of the pumping activity of the macrozoobenthos larvae is a significant step for a better understanding of the larvae's role in activity of the ecosystem. Furthermore, such a quantification provides a reliable input for mathematical

Table 3 Time-averaged volumetric flow rates $(\bar{Q})$ and corresponding average pumping velocities $\left(\bar{v}_{a v}\right)$ for all setups

\begin{tabular}{lllllr}
\hline Setup & $\bar{Q}(\mathrm{~mm} 3 / \mathrm{s})$ & $d_{\mathrm{b}}(\mathrm{mm})$ & $\bar{v}_{a v}(\mathrm{~mm} / \mathrm{s})$ & $\sigma_{Q}$ & $n_{\mathrm{i}}$ \\
\hline Setup I & 61.1 & 2.25 & 15.4 & 26.8 & 216 \\
Setup II (inlet) & 54.6 & 2.25 & 13.7 & 17.3 & 200 \\
Setup II (outlet) & 58 & 2.25 & 14.6 & - & 1 \\
Setup III & 80.6 & 3.2 & 10.0 & 24.1 & 206 \\
\hline
\end{tabular}

$\sigma_{Q}, d_{\mathrm{b}}$ and $n_{\mathrm{i}}$ denote the standard deviation in the volumetric flow rate, burrow diameter and the number of the PIV-image pairs, respectively 
models estimating their biogeochemical impacts. To do this, we measured the water velocity field near burrow inlets and outlets using non-invasive particle image velocimetry. The measurements showed that the larva's pumping activity is not continuous, but interspersed with periods of non-pumping. Hence, the measured velocities and pumping rates refer to those obtained within pumping periods only.

The measurements demonstrated that the macrozoobenthos species reported here are able to generate time-averaged maximum flow velocities ranging from 17.9 to $30.5 \mathrm{~mm} \mathrm{~s}^{-1}$ above the inlets (see Table 2). We would like to recall that in setup I the larvae were left to themselves to construct their 'natural burrows', while setup II is a quasi- natural burrow, having a wire U-tube of predefined shape, in which the larvae were almost free to build their burrow. In comparison, setup III provided a fully artificial burrow. The maximum velocity of $30.5 \mathrm{~mm} \mathrm{~s}^{-1}$ corresponds to setup II, and is higher than average maximum velocity for setup I. Since the maximum velocity appears at a concrete point, and its position varies in each setup, consequently, $\bar{v}_{\max }$ (shown in Table 2) depends on many issues such as the closeness of the position to any wall and the differences in entrance topography shape. Hence, in order to provide more representative field quantities, first all velocity components entering a certain burrow were integrated to obtain a volumetric flow rate (second column in Table 3).

Using this volumetric flow rate, we need burrow diameters to compute the averaged velocities. In setup III, the diameter of the burrow was assumed to be the same as the fixed diameter of the Tygon U-tube, i.e., equal to $3.2 \mathrm{~mm}$. In other cases, however, the burrow diameter was estimated by the diameters of the burrow inlet and burrow outlet visible at the sediment surface. Hence, in our analysis, we took an average burrow diameter of $2.25 \mathrm{~mm}$, which is slightly larger than the larva's body diameter observed in the present study and burrow diameters reported by Stief and de Beer (2002) for the fourth larva instar of Chironomus riparius, known to resemble the $C$. plumosus used in our study (third column in Table 3). The final averaged velocities (fourth column in Table 3 ) are more representative due to the fact that it lies on an integral, stream tube basis. The results show very similar values for the cases of natural and quasinatural setups. Therefore, an average input velocity of $15 \mathrm{~mm} \mathrm{~s}^{-1}$ inside the burrow and an averaged volumetric flow rate of $60 \mathrm{~mm}^{3} \mathrm{~s}^{-1}$ can be estimated for the natural and quasi-natural burrows.

In contrast, in setup III (artificial system) lower average velocities were measured at the inlet of the setup III (see column four in Table 3), and can be explained as follows. In setup III, the cross-section through which all streamlines enter is equivalent to the tube area itself. As the diameter of the tube $(3.2 \mathrm{~mm})$ is greater than the burrow diameter in other two setups, a larger cross-section, and with it, a large volumetric flow rate will be produced. Consequently, given a larger cross-section, a higher volumetric flow rate is generated in setup III, which is coherent with the intuition and in accordance with Eq. (1). With this, the comparison of measurements in all setups shows that the volumetric flow rate is almost equal in those setups that contained sediment (setup I and II), and that the stream tube concept is an appropriate method for quantification of the pumping rate.

An additional important feature of larvae's pumping activity is inhibited in the highly fluctuating values of the maximum velocity, and the pumping flow rate about their mean values. Obviously, such high 'deviations' from the mean values indicate fluctuations due to pulsing patterns shown in Fig. 4 . These should not be taken as uncertainties in the PIV measurements. Apparently, and in contrast to other organisms like Urechis caupo that are using peristaltic body contractions for pumping (Osovitz and Julian 2002), C. plumosus coils its body sinusoidally to pump water through the burrow. Hence, the observed pulsation can be considered as a result of this sinusoidal body shape due to coiling. The ecological advantage of the pulsation might be that the water leaving the burrow is catapulted extremely far into the overlying water body reducing the risk of short circuits. Obviously, short circuits are not optimal for chironomids due to lower oxygen content and reduced nutritious planktons in the expelled water.

Finally, an interesting issue observed during the flow visualization near the outlet was that not all particles entered into the inlet could exit from the outlet. This is partially due to the fact that C. plumosus larvae stabilize the burrow walls with silk-like threads, which could partly trap the tracer particles. Additionally, $C$. plumosus can weave conical webs inside the burrow to conduct filter feeding, which implies the web is eaten together with the attached plankton in every few minutes (Pinder 1986; Leuchs 
and Neumann 1990). Tracer particles got caught in these webs as well as at the burrow walls, and thus measurements were hindered by drastically decreased particle concentrations at the outlets. Furthermore, the filtering role of the uneven burrow walls and the porosity of the sediment itself can mediate additional resistance to tracer passages. To overcome this problem, during pumping, much more tracer particles were injected into the corresponding inlet region to increase the particle concentration at the outlet.

Acknowledgments Two of the authors (JL and AR) are thankful to German Research Foundation (DFG) for the financial support received under the grant (LE 1356/3-1). They also thank Mathias Kirf and Andreas Brand from Swiss Federal Institute of Aquatic Science and Technology (EAWAG), for their idea to use PIV to determine flow velocities in chironomids burrows and arrange the contact between the authors. Furthermore, the authors are thankful to X. F. Garcia from Leibniz-Institute of Freshwater Ecology and Inland Fisheries for identification of the larvae.

Open Access This article is distributed under the terms of the Creative Commons Attribution Noncommercial License which permits any noncommercial use, distribution, and reproduction in any medium, provided the original author(s) and source are credited.

\section{References}

Aller RC (1994) Bioturbation and remineralization of sedimentary organic matter: effects of redox oscillation. Chem Geol 114:331-345

Andersen FO, Jensen HS (1991) The influence of chironomids on decomposition of organic matter and nutrient exchange in a lake sediment. Verh Int Verein Limnol 24:3051-3055

Anderson JG, Meadows PS (1978) Microenvironments in marine sediments. Proc R Soc Ed 76(B):1-16

Andersson G, Granéli W, Stenson J (1988) The influence of animals on phosphorus cycling in lake ecosystems. Hydrobiologia 170:267-284

Boudreau BP, Choi J, Meysman F, Francois-Carcaillet F (2001) Diffusion in a lattice automaton model of bioturbation by small deposit feeders. J Mar Res 59(5):749-768

Driescher E, Behrendt H, Schellenberger G, Stellmacher R (1993) Lake Müggelsee and its environment - natural conditions and anthropogenic impacts. Int Rev Ges Hydrobiol 78:327-343

Eckert B, Walz N (1999) Zooplankton succession and thermal stratification in the polymictic shallow Müggelsee (Berlin, Germany): a case for the intermediate disturbance hypothesis? Hydrobiologia 387:199-206

Epler JH (2001) Identification manual for the larval chironomidae (Diptera) of north and south Carolina. Version 1.0, Genus Chironomus, pp 8.39-8.44
Furukawa Y, Bentley SJ, Lavoie DL (2001) Bioirrigation modelling in experimental benthic mesocosms. J Mar Res 59:417-452

Graneli W (1979) The influence of Chironomus-plumosus larvae on the oxygen-uptake of sediment. Arch Hydrobiol 87:385-403

Johnson RK, Boström B, van de Bund W (1989) Interactions between Chironomus plumosus (L.) and the microbial community in surficial sediments of a shallow, eutrophic lake. Limnol Oceanogr 34(6):992-1003

Kißner T, Riss HW, Stief P, Meyer EI (2003) Bioturbationsund Bauverhalten von Chironoumus plumosus (Diptera: Chironomidae) unter verschiedenen Sauerstoffbedingungen. Deutsche Gesellschaft für Limnologie. Tagungsbericht 2003 Berlin, pp 486-489

Koretsky CM, Meile C, Van Cappellen P (2002) Quantifying bioirrigation using ecological parameters: a stochastic approach. Geochem Trans 3:17-30

Kozerski HP, Kleeberg A (1998) The sediments and benthicpelagic exchange in the shallow Lake Müggelsee. Int Rev Hydrobiol 83:77-112

Langton PH, Pinder LCV (2007) Keys to the adult male Chironomidae of Britain and Ireland. Freshwater Biological Association, vols. 1 and 2. Scientific Publication 64, pp $239+168$. ISBN 0-900386-75-6

Leuchs H (1986) The ventilation activity of Chironomus larvae (Diptera) from shallow and deep lakes and the resulting water circulation in correlation to temperature and oxygen conditions. Arch Fr Hydrobiol 108:281-299

Leuchs H, Neumann D (1990) Tube texture, spinning and feeding behavior of Chironomus larvae. Zool Jb Syst 117:31-40

Lewandowski J, Hupfer M (2005) Effect of macrozoobenthos on two-dimensional smallscale heterogeneity of pore water phosphorus concentrations in lake sediments: A laboratory study. Limnol Oceanogr 50(4):1106-1118

Lewandowski J, Laskov C, Hupfer M (2007) The relationship between Chironomus plumosus burrows and the spatial distribution of pore-water phosphate, iron and ammonium in lake sediments. Freshw Biol 52(2):331-343

Meile C, Tuncay K, Van Cappellen P (2003) Explicit representation of spatial heterogeneity in reactive transport models: application to bioirrigated sediments. J Geochem Expl 78-79:231-234

Meysman FJR, Galaktionov OS, Gribsholt B, Middelburg JJ (2006) Bioirrigation in permeable sediments: advective pore-water transport induced by burrow ventilation. Limnol Oceanogr 51(1):142-156

Nixdorf B (1994) Polymixis of a shallow lake (Großer Müggelsee, Berlin) and its influence on seasonal phytoplankton dynamics. Hydrobiologia 275/276:173-186

Osovitz CJ, Julian D (2002) Burrow irrigation behavior of Urechis caupo, a filterfeeding marine invertebrate, in its natural habitat. Mar Ecol Prog Ser 245:149-155

Pinder L (1986) Biology of freshwater Chironomidae. Ann Rev Entomol 31:1-23

Polerecky L, Volkenborn N, Stief P (2006) High temporal resolution oxygen imaging in bioirrigated sediments. Environ Sci Technol 40:5762-5769

Riisgård HU, Larsen PS (2005) Water pumping and analysis of flow in burrowing zoobenthos-an overview. Aquat Ecol 39:237-258 
Stamhuis EJ, Videler JJ (1998) Burrow ventilation in the tubedwelling shrimp Callianassa subterranea (Decapoda: Thalassinidea). II. The flow in the vicinity of the shrimp and the energetic advantages of a laminar non-pulsating ventilation current. J Exp Biol 201:2159-2170

Stief P, de Beer D (2002) Bioturbation effects of Chironomus riparius on the benthic $\mathrm{N}$-cycle as measured using microsensors and microbiological assays. Aquat Microb Ecol 27:175-185

Timmermann K, Christensen JH, Banta GT (2002) Modeling of advective solute transport in sandy sediments inhabited by the lugworm Arenicola marina. J Mar Res 60(1):151-169
Timmermann K, Banta GT, Glud RN (2006) Linking Arenicola marina irrigation behavior to oxygen transport and dynamics in sandy sediments. J Mar Res 64(6):915-938

Volkenborn N, Hedtkamp SIC, van Beusekom JEE, Reise K (2007) Effects of bioturbation and bioirrigation by lugworms (Arenicola marina) on physical and chemical sediment properties and implications for intertidal habitat succession. Estuar Coast Shelf Sci 74(1-2):331-343

Wilhelm S, Hintze T, Livingstone DM, Adrian R (2006) Longterm response of daily epilimnetic temperature extrema to climate forcing. Can J Fish Aquat Sci 63:467-2477 